\title{
Decoding the Neuroanatomical Basis of Reading Ability: A Multivoxel Morphometric Study
}

\author{
Qinghua He, ${ }^{1,2}$ Gui Xue, ${ }^{1}$ Chunhui Chen, ${ }^{1}$ Chuansheng Chen, ${ }^{3}$ Zhong-Lin Lu, ${ }^{4}$ and Qi Dong ${ }^{1}$ \\ ${ }^{1}$ National Key Laboratory of Cognitive Neuroscience and Learning, Beijing Normal University, Beijing, 100875, China, ${ }^{2}$ Brain and Creativity Institute, \\ University of Southern California, Los Angeles, California 90089, 32Department of Psychology and Social Behavior, University of California Irvine, Irvine, \\ California 92697, and ${ }^{4}$ Center for Cognitive and Behavioral Brain Imaging, The Ohio State University, Columbus, Ohio 43210
}

As a relatively recent cultural invention in human evolution, reading is an important gateway to personal development and socioeconomic success. Despite the well documented individual differences in reading ability, its neuroanatomical correlates have not been well understood, largely due to the fact that reading is a complex skill that consists of multiple components. Using a large sample of 416 college students and 7 reading tasks, the present study successfully identified three uncorrelated components of reading ability: phonological decoding, form-sound association, and naming speed. We then tried to predict individuals' scores in these components from their gray matter volume $(\mathrm{GMV})$ on a subset of participants $(N=253)$ with high-quality structural images, adopting a multivariate support vector regression analysis with tenfold cross-validation. Our results revealed distinct neural regions that supported different aspects of reading ability: whereas phonological decoding was associated with the GMV in the left superior parietal lobe extending to the supramarginal gyrus, form-sound association was predicted by the GMV in the hippocampus and cerebellum. Naming speed was associated with GMV in distributed brain regions in the occipital, temporal, parietal, and frontal cortices. Phonological decoding and form-sound association were uncorrelated with general cognitive abilities. However, naming speed was correlated with intelligence and processing speed, and some of the regions that were predictive of naming speed also predicted these general cognitive abilities. These results provide further insights on the cognitive and neural architecture of reading and the structural basis of individual differences in reading abilities.

\section{Introduction}

Reading is an integral part of life in today's information-driven society. Probably due to the lack of a specialized "module" for reading in the relatively short history of evolution, years of formal education and training are generally required to achieve fluent reading, during which existing neural systems are recycled and gradually optimized to process written materials (Schlaggar et al., 2002; McCandliss et al., 2003; Xue et al., 2006a; Dehaene and Cohen, 2007; Schlaggar and McCandliss, 2007; Xue and Poldrack, 2007; Carreiras et al., 2009; Brem et al., 2010; Dehaene et al., 2010). Probably for the same reason, a wide spectrum of individual differences in learning to read have been well documented, ranging from fast readers to those with reading difficulties (e.g., dyslexia).

Both functional and anatomical imaging techniques have been used to examine the neural architecture of reading and the neural basis of individual differences (Price, 2012). The overlap

\footnotetext{
Received Jan. 30, 2013; revised June 2, 2013; accepted July 1, 2013.

Author contributions: Q.H., G.X., Chuansheng C., Z.-L.L., and Q.D. designed research; Q.H. and Chunhui C. performed research; Q.H. contributed unpublished reagents/analytic tools; Q.H. and G.X. analyzed data; Q.H., G.X., Chunhui C., Chuansheng C., Z.-L.L., and Q.D. wrote the paper.

This research was supported by the 111 project (B07008), the National Science Foundation of China (31130025), the Foundation for the Authors of National Excellent Doctoral Dissertations of China (201108), and the National Institute of Health (HD057884-01A2). We thank all laboratory members who helped with the data collection.

The authors declare no competing financial interests.

Correspondence should be addressed to Gui Xue, National Key Laboratory of Cognitive Neuroscience and Learning, Beijing Normal University, Beijing, 100875, China, E-mail: guixue@gmail.com.

DOI:10.1523/JNEUROSCI.0449-13.2013

Copyright $\odot 2013$ the authors $\quad 0270-6474 / 13 / 3312835-09 \$ 15.00 / 0$
}

in brain regions identified by both methods suggests a link between regional brain morphology and function (Hoeft et al., 2007; Linkersdörfer et al., 2012). Compared with functional imaging, the anatomical approach requires less participant cooperation, and is most cost-effective and less contaminated by performance differences, providing an ideal tool for a largescale study of participants with various ages and reading abilities. This method has been widely used to examine the neural basis of reading difficulties (Vinckenbosch et al., 2005; Hoeft et al., 2007; Frye et al., 2010; Welcome et al., 2011; Richlan et al., 2013), and also the neural basis of individual differences in reading ability among typical adults (Blackmon et al., 2010, 2011; Zhang et al., 2013).

As most of these studies used a single reading task (or several reading tasks but analyzed them separately) and relatively small sample sizes, a comprehensive and reliable picture might be hard to achieve for two major reasons. First, reading is a complex skill involving different processes. At least three critical components/ processes of reading ability, namely, phonological decoding, form-sound association, and naming speed, have been identified in behavioral studies (Hoover and Gough, 1990; Joshi and Aaron, 2000). At the neural level, distributed brain regions are involved in even very simple reading tasks (Fiez and Petersen, 1998; Price, 2012). Because reading ability involves multiple subcomponents and multiple brain regions, it may not be possible to use a single reading task (even a comprehensive one) to dissociate the subsystems that contribute to all aspects of the variances in reading ability. Second, the correlational approach with small sample 
sizes generally over-fits the data and is thus vulnerable to noise (Vul et al., 2009; Cohen et al., 2011).

To address these issues, the present study used several reading tasks and a factor analysis on a large sample $(N=416)$ to identify uncorrelated/orthogonal components of reading ability. A multivariable support vector regression analysis with tenfold crossvalidation was then used to provide a predictive decoding of individuals' reading performance from their gray matter volume (GMV).

\section{Materials and Methods}

Participants. Four-hundred and sixteen (187 males, 229 females) healthy Han Chinese college students (18-24 years old, mean age $=21.5$ years, $\mathrm{SD}=0.98)$ were recruited. All of them learned English as a second language for $>9$ years. They have normal or corrected-to-normal vision and have no history of psychiatric or neurological disease and were strongly right-handed as judged by Snyder and Harris's handedness inventory (Snyder and Harris, 1993). Two-hundred and fifty-three (150 females) of them finished one high-resolution structural MRI scan. An additional 12 participants were tested but excluded from analysis due to missing data in one or more reading tests caused by technical errors. Written consent approved by Institutional Review Board of Beijing Normal University was obtained from each participant after a full explanation of the study purpose and procedure.

Behavioral tasks. Participants were asked to complete seven reading tasks. (1) The Visual-Auditory Learning test (in English), adopted from Woodcock Reading Mastery Test-Revised form G (Woodcock, 1997). It assesses the ability to form associations between visual stimuli (nonlanguage symbols) and oral responses. Participants learned 26 symbols and their names, as well as two symbols for word endings (-ing, -s), and then read them in sentence form across seven brief test stories. Participants must respond within $5 \mathrm{~s}$ to each symbol. The final score was the number of correct responses of 134 total items. (2) The Sight Word Efficiency test (Forms A and B), adopted from the Test of Word Reading Efficiency (TOWRE; Torgesen et al., 1999), which assesses the number of printed words (104 words in each form) that can be accurately read within $45 \mathrm{~s}$. (3) The Phonetic Decoding Efficiency test (Forms A and B), adopted from TOWRE (Torgesen et al., 1999) and indexed by the number of pronounceable printed nonwords (i.e., pseudowords, 104 items in each form) that can be accurately decoded within $45 \mathrm{~s}$. (4) The Chinese Rapid Color Naming test, and (5) the Chinese Rapid Object Naming test. Both were adopted from the Comprehensive Test of Phonology Processing (Wagner et al., 1999). Participants were asked to name colors (black, green, blue, red, brown, and yellow) or objects (boat, star, pencil, chair, fish, and key) in Chinese as fast as they could. For each subtest, 72 items were arranged in two arrays on separate pages, each including four rows of nine items, and the performance was determined by adding the total number of seconds to complete both arrays. (6) The Chinese Sight Word Efficiency test, modified from the English Sight Word Efficiency test. The 104 high-frequency items in this test were selected from a Chinese character psycholinguistic norm (Liu et al., 2007). (7) The Chinese Vocabulary test. Participants were asked to read 40 very low-frequency Chinese characters selected from a Chinese character psycholinguistic norm (Liu et al., 2007). The performance in this test was scored by adding the total number of characters that were correctly read.

Participants also completed several tests that measured their general cognitive capacities, including intelligence, item memory, and reaction time. More details of these tests can be found in our previous publications (He et al., 2010, 2012; Zhu et al., 2010). Briefly, intelligence was measured by the Wechsler Adult Intelligence Scale-Revised Chinese Version with six subscales (three verbal and three performance tests). The verbal section included general knowledge (tapping general information acquired from one's culture), similarities (abstract verbal reasoning), and digit span (attention and concentration). The performance section included picture completion (ability to quickly perceive visual details), symbol digit coding (visual-motor coordination and motor and mental speed), and block design (spatial perception, visual abstract processing, and problem solving). Memory capacity was measured by the Wechsler
Memory Scale using two subscales (recall and recognition). In the recall subscale, participants were asked to study 20 pictures of common objects for $90 \mathrm{~s}$, and then freely recall these items right after learning. In the recognition subscale, eight items of common objects or Chinese characters were simultaneously presented for $30 \mathrm{~s}$. Participants were asked to pick out the eight studied items from a total of 28 items (including eight studied and 20 similar but nonstudied items) right after presentation. The numbers of correctly recalled and recognized items were scored and then entered into a factor analysis to generate a single memory score. Reaction time (RT) was measured by three tests, namely, the simple, choice, and discrimination RT tests. In the simple RT test, participants were instructed to press the button whenever they saw the stimulus (a green or red square) on the computer screen. In the choice RT test, participants were asked to respond to the green square only. In the discrimination RT test, participants were asked to press the left button for the green square and the right button for the red square. The averaged RTs in the three tests were entered into an exploratory factor analysis to generate a single RT score.

Factor analysis of the behavioral data. Using SPSS (version 20.0), two exploratory factor analyses were performed on behavior measures: one on all the 416 participants and one on the 253 participants with high quality structural scans. Principal component analysis was used to extract components. Varimax with Kaiser Normalization was used to rotate the loading matrix, and regression was used to calculate component scores from each task.

MRI protocol. Participants underwent one scan for high-resolution structural images of the whole brain on a 3T Siemens Magnetom Trio system (Siemens) with Total imaging matrix in the Imaging Center for Brain Research, Beijing Normal University. T1-weighted 3DMagnetization prepared rapid gradient echo (MPRAGE) protocol was acquired using the following parameters: TR/TE $=2530 / 3.1 \mathrm{~ms}$, flip angel $=10^{\circ}, \mathrm{FOV}=256$, matrix $=256 \times 256$. Two-hundred and eight sagittal slices were acquired with $1 \mathrm{~mm}$ thickness, resulting final resolution to be $1 \times 1 \times 1 \mathrm{~mm}$.

Structural MRI processing. Structural MRI data were analyzed with The Oxford Centre for Functional MRI of the Brain (FMRIB) Software Library voxel-based morphometry (FSL-VBM), a VBM style analysis toolbox (Good et al., 2001) implemented in FSL. Brains from the structural images were extracted, tissue-type segmented, and then aligned to the gray-matter template in the MNI152 standard space. The spatially normalized images were then averaged to create a study-specific template, to which the native gray matter images were registered again using both linear and nonlinear algorithms. The registered partial volume images were then modulated by dividing them with the Jacobian of the warp field to correct for local expansion or contraction. The modulated segmented images, which represent the GMV, were then smoothed with an isotropic Gaussian kernel with a $\sigma$ of $3 \mathrm{~mm}$.

Multivariate VBM analysis. The preprocessed imaging data were used to predict individual reading scores using an Epsilon-insensitive support vector regression (SVR; Drucker et al., 1997) with a linear kernel, as implemented in PyMVPA (Multivariate Pattern Analysis in Python; http://www.pymvpa. org/; Hanke et al., 2009). A searchlight procedure with a three-voxel radius (Kriegeskorte et al., 2006) was used to provide a measure of decoding accuracy in the neighborhood of each voxel. Following Jimura and Poldrack (2012), we set the $\varepsilon$ parameter in the SVR to be 0.01 .

A tenfold cross-validation was applied across participants to obtain estimates for each participant. The 253 participants were divided into 10 groups of 25 or 26 participants, with matched gender ratio and reading performance. Different grouping was used for each of the three reading scores. In each iteration, an SVR model was trained based on 226 or 227 participants. Once trained, this SVR model then generated a prediction for the score of the excluded 25 or 26 participants based on their imaging data. Voxelwise accuracy of SVR prediction was then calculated, defined as the Pearson's correlation coefficient between actual and predicted values of the reading scores. The same analysis was done for general cognitive abilities to confirm whether these regions were specifically predictive of reading abilities.

Permutation test of false-positive rate. We used a randomization test to estimate the distribution of classifier accuracy under the null hypothesis of no association between GMV and reading ability. For each analysis, the 
Table 1. Descriptive statistics of reading and cognitive tests

\begin{tabular}{lccc}
\hline & Range & Mean & SD \\
\hline Visual-auditory learning & $81-139$ & 122.6 & 10.12 \\
Sight word efficiency-Form A & $32-95$ & 72.2 & 9.28 \\
Sight word efficiency-Form B & $32-98$ & 73.3 & 9.53 \\
Phonetic decoding efficiency-Form A & $0-62$ & 42.6 & 8.45 \\
Phonetic decoding efficiency-Form B & $0-63$ & 43.9 & 8.6 \\
Chinese rapid color naming & $21-91$ & 49.3 & 9.69 \\
Chinese rapid object naming & $28-81$ & 43.1 & 6.84 \\
Chinese sight word efficiency & $40-103$ & 86.8 & 11.65 \\
Chinese vocabulary & $4-50$ & 31.7 & 7.74 \\
Wechsler adult intelligence scale-revised & $100-147$ & 125.7 & 7.8 \\
Wechsler memory scale-recall & $8-16$ & 14.6 & 1.42 \\
Wechsler memory scale-recognition & $10-20$ & 17.5 & 1.93 \\
Simple RT (ms) & $180.5-357.6$ & 247.9 & 33.38 \\
Choice RT (ms) & $262.1-634.7$ & 393.1 & 55.86 \\
Discriminate RT (ms) & $256.3-677.9$ & 407.2 & 67.78 \\
\hline
\end{tabular}

individuals' factor scores were randomly shuffled, and then the same SVR was performed. The shuffle was done within each group to make sure it did not change the gender ratio and distribution of reading performance within each group. This procedure was repeated 1000 times to generate a distribution of the association. Because a whole-brain searchlight permutation is extremely computationally intensive ( $>24,000$ processing hours), we thus did the permutation test only on each cluster/ sphere with a prediction accuracy $>0.15$ (approximately corresponding to an uncorrected threshold of $p=0.01$ ) and a cluster size $>125$ voxels. As shown in Tables 4-6, the prediction accuracies in these regions were all above 95th and some were above 99th percentile of the permutation.

To test whether a brain region was specifically predictive of a given reading task, we examined whether the prediction accuracy for one reading component was significantly larger than that for another component. To do this, we first transformed the correlation coefficients to Fisher's Z and then performed $t$ tests on the Z-scores.

Univariate analysis. Voxelwise general linear model was used to examine the direction (positive or negative) of the correlation between the GMV and behavior measures. Nonparametric permutation methods (Randomize v2.1 in FSL) were used for inference on statistic maps (Nichols and Holmes, 2002). Null distribution at each voxel was constructed using 10,000 random permutations of the data. False discovery rate (FDR) with a threshold of $p<0.05$ was used to correct for multiple comparisons across the whole brain. The mean GMV in each significant cluster was then extracted for each individual. To compare the correlation coefficients across components, we again transformed them to Fisher's $\mathrm{Z}$ and then performed $t$ tests on the $\mathrm{Z}$-scores.

\section{Results}

Behavioral results

Table 1 shows the range, mean, and SD of the 11 measures generated from the seven reading tests, as well as six measures from the cognitive tests. Kaiser-Meyer-Olkin (KMO) test measure of sampling adequacy $(\mathrm{KMO}=0.80)$ and Bartlett's test of sphericity $\left[\chi^{2}(36)=1925.65, p<0.001\right]$ suggested that our data were suitable for factor analysis. Principal component analysis extracted three components with factor eigenvalues $>1$, which in total explained $73.22 \%$ of the variance.

Table 2 shows the rotated components loading matrix after Varimax rotation for each measure. The first component, with high loadings for Sight Word Efficiency (both Form A and Form B) and Phonetic Decoding Efficiency (both Form A and Form B), was thus named phonological decoding. The second component, with high loadings for Visual-Auditory Learning and Chinese Vocabulary, was thus named form-sound association. The third component was named naming speed because it had high loadings for two rapid naming tasks (Rapid Color Naming and Rapid Object Naming) and the Chinese Sight Word Efficiency test.
Table 2. Exploratory factor analysis of all reading tasks revealed three major components

\begin{tabular}{llll}
\hline & $\begin{array}{l}\text { Phonological } \\
\text { decoding }\end{array}$ & $\begin{array}{l}\text { Form-sound } \\
\text { association }\end{array}$ & $\begin{array}{l}\text { Naming } \\
\text { speed }\end{array}$ \\
\hline $\begin{array}{l}\text { Phonetic decoding efficiency-Form A } \\
\text { Phonetic decoding efficiency-Form B }\end{array}$ & 0.887 & & \\
Sight word efficiency-Form A & 0.894 & & \\
Sight word efficiency-Form B & 0.862 & & \\
Visual-auditory learning & & 0.864 & \\
Chinese vocabulary & & 0.650 & \\
Rapid color naming & & 0.829 \\
Rapid object naming & & 0.829 \\
Chinese sight word efficiency & & & 0.540 \\
\hline Loadings smaller than 0.5 are not shown in this table. & &
\end{tabular}

Table 3. Correlations between reading components and cognitive abilities

\begin{tabular}{lccc}
\hline & Phonological decoding & Form-sound association & Naming speed \\
\hline IQ & -0.01 & 0.05 & $0.29^{* *}$ \\
Memory & 0.06 & 0.09 & -0.05 \\
RT & -0.05 & -0.08 & $-0.19^{* *}$ \\
\hline
\end{tabular}

${ }^{* *} p<0.01$.

Factor analysis results were highly consistent either using the whole sample or the sample with MPRAGE scans. The factor scores generated from these two analyses were highly correlated $\left(r_{(253)}=0.987, p<0.001\right.$ for phonological decoding; $r_{(253)}=$ $0.895, p<0.001$ for form-sound association; and $r_{(253)}=0.978$, $p<0.001$ for naming speed). We used the factor results from the whole sample for subsequent analyses.

\section{Correlation between reading abilities and general cognitive capacities}

To examine whether these component scores reflect reading-specific abilities or general cognitive capacities, we computed their correlations with general intelligence, memory, and reaction time scores. As summarized in Table 3, naming speed was significantly correlated with IQ score $(r=0.29, p<0.001)$ and reaction time $(r=-0.19$, $p<0.01$ ), suggesting it might partially reflect some general cognitive capacities. No other correlations were significant (all $r<0.09$, all $p>$ $0.07)$, suggesting that phonological decoding and form-sound association might be reading-specific. Of course, the three reading components were independent of each other within the whole sample (all $r=0)$ and within the MRPAGE sample $(r<0.07, p>0.15)$, allowing us to disentangle their neuroanatomical bases.

\section{Multivariate results}

Multivariate pattern analysis (MVPA) results suggested that phonological decoding could be successfully predicted by GMV in the left superior parietal lobe extending to the supramarginal gyrus (SPL/SMG; MNI $=-30,-36,42$, prediction accuracy $r=$ $0.26)$, posterior cingulate cortex extending to the precuneus (PCC/PreCu; MNI $=-8,-52,24, r=0.25)$, right superior frontal gyrus (SFG; $\mathrm{MNI}=14,40,54, r=0.18$ ), and right lateral occipital cortex (LOC; $\mathrm{MNI}=26,-94,12, r=0.18$ ). ROI analysis suggested that the correlation was positive between phonological decoding and GMV in the left SPL/SMG, right SFG, and right LOC, whereas a negative correlation was found between GMV in the left PCC/PreCu and phonological decoding. In all these four brain regions, prediction accuracy was significantly higher for phonological decoding than for other reading components or general cognitive abilities (Table 4; Fig. 1).

For form-sound association, strong predictive accuracy was found in the bilateral cerebellum (two clusters in left: MNI $=-28$, 
Table 4. Brain regions showing significant correlations between GMV and phonological decoding in MVPA analysis

\begin{tabular}{|c|c|c|c|c|c|c|c|c|c|c|c|c|c|}
\hline \multirow[b]{2}{*}{ Brain Regions } & \multirow[b]{2}{*}{$L / R$} & \multirow[b]{2}{*}{ No. Voxels } & \multicolumn{3}{|c|}{ MNI Coordinates } & \multirow[b]{2}{*}{$95 \%$} & \multirow[b]{2}{*}{$99 \%$} & \multicolumn{6}{|c|}{ Prediction Accuracy } \\
\hline & & & $x$ & y & $z$ & & & $D$ & $A$ & $S$ & 10 & M & RT \\
\hline PCC/PreCu & L & 721 & -8 & -52 & 24 & 0.12 & 0.15 & 0.26 & $0.06 * *$ & $-0.06^{* *}$ & $0.12^{* *}$ & $0.09^{* *}$ & $0.06^{* *}$ \\
\hline SPL/SMG & L & 422 & -30 & -36 & 42 & 0.13 & 0.17 & 0.25 & $0.07^{* *}$ & $-0.09^{* *}$ & $0.01^{* *}$ & $-0.02^{* *}$ & $0.09^{* *}$ \\
\hline SFG & $\mathrm{R}$ & 201 & 14 & 40 & 54 & 0.12 & 0.16 & 0.18 & $0.07^{*}$ & $0.06^{*}$ & $0.04^{*}$ & $0.03^{* *}$ & $0.09^{\mathrm{a}}$ \\
\hline LOC & $\mathrm{R}$ & 174 & 26 & -94 & 12 & 0.13 & 0.17 & 0.18 & $0.03^{* *}$ & $-0.07^{* *}$ & $0.08^{*}$ & $-0.07^{* *}$ & $-0.08^{* *}$ \\
\hline
\end{tabular}

D, Phonological decoding; A, form-sound association; S, naming speed; $\mathrm{M}$, memory ability; RT, reaction time; $\mathrm{PCC}$, posterior cingulate cortex; PreCu, precuneus; $\mathrm{PPL}$, superior parietal lobe; SMG, supramarginal gyrus; SFG, superior frontal gyrus; LOC, lateral occipital cortex.

${ }^{* *} p<0.01,{ }^{*} p<0.05,{ }^{a} p<0.10$. Significance denotes test of prediction accuracy difference between phonological decoding and other two reading components as well as measures of cognitive abilities.
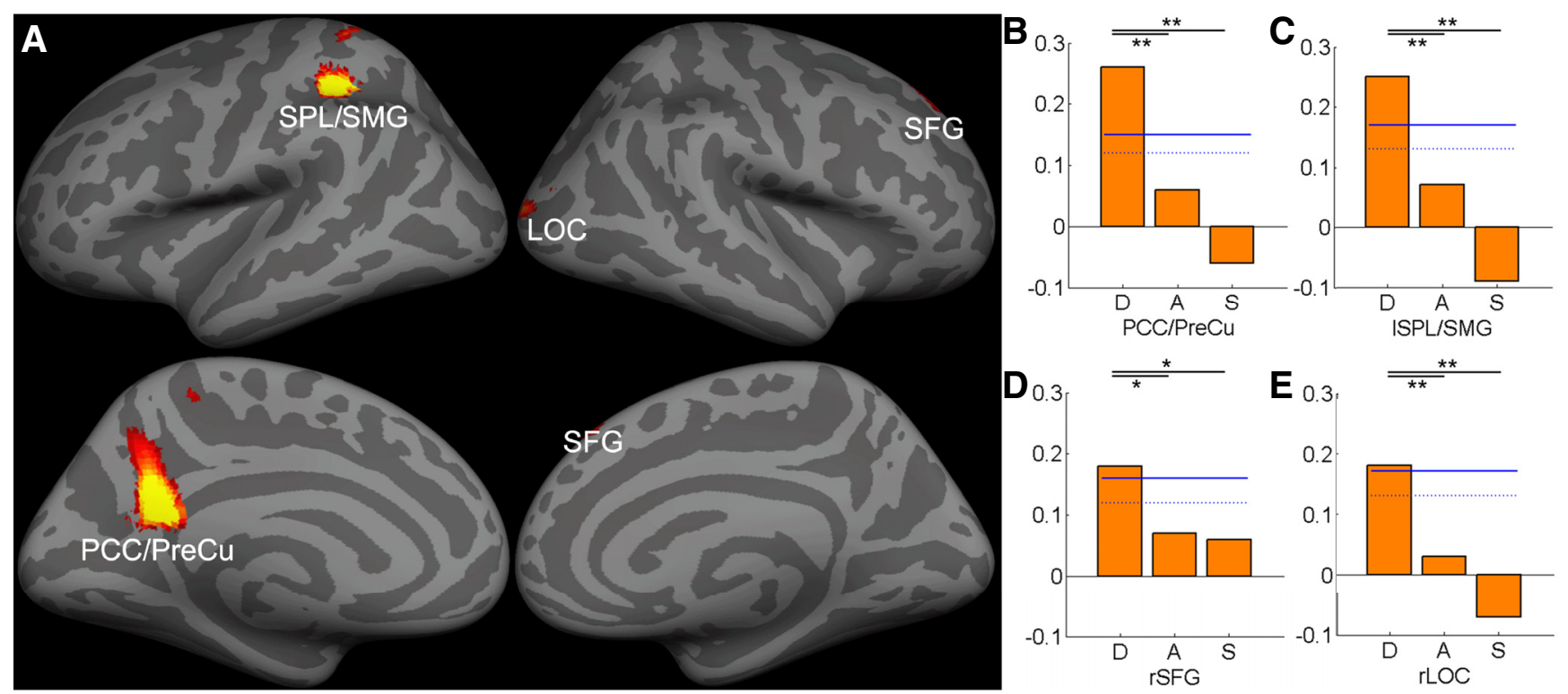

Figure 1. A, MVPA revealed significant correlations between GMV and phonological decoding. The multivariate SVR decoding accuracy was mapped onto the inflated gray matter surface using FreeSurfer (http://surfer.nmr.mgh.harvard.edu/). The bar graphs show the prediction accuracy in $\boldsymbol{B}, \mathrm{PCC} / \mathrm{PreCu},(\boldsymbol{C})$ left SPL/SMG, (D) right SFG, and (E) right $L O C$. The dotted and solid blue lines represent the 95 th and 99 th percentile of the distribution of the permutation results, respectively $\left({ }^{*} p<0.05 ;{ }^{* *} p<0.01\right)$. D, Phonological decoding: A, form-sound association; S, naming speed. See Table 4 for ROl abbreviations.

Table 5. Brain regions showing significant correlations between GMV and form-sound association in MVPA analysis

\begin{tabular}{|c|c|c|c|c|c|c|c|c|c|c|c|c|c|}
\hline \multirow[b]{2}{*}{ Brain Regions } & \multirow[b]{2}{*}{$\mathrm{L} / \mathrm{R}$} & \multirow[b]{2}{*}{ No. Voxels } & \multicolumn{3}{|c|}{ MNI Coordinates } & \multirow[b]{2}{*}{$95 \%$} & \multirow[b]{2}{*}{$99 \%$} & \multicolumn{6}{|c|}{ Prediction Accuracy } \\
\hline & & & $x$ & $y$ & Z & & & $D$ & A & $S$ & IQ & M & RT \\
\hline Cerebellum & $\mathrm{L}$ & 1354 & -28 & -86 & -40 & 0.13 & 0.17 & $0.06^{* *}$ & 0.23 & $0.08^{* *}$ & $0.04^{* *}$ & $0.06^{* *}$ & $-0.09^{* *}$ \\
\hline Hipp & $\mathrm{R}$ & 486 & 28 & -30 & -6 & 0.13 & 0.17 & $0.01^{* *}$ & 0.19 & $-0.02^{* *}$ & $-0.01^{* *}$ & $0.08^{*}$ & $0.05^{*}$ \\
\hline Cerebellum & $\mathrm{R}$ & 436 & 36 & -60 & -44 & 0.12 & 0.16 & $-0.09^{* *}$ & 0.22 & $0.07^{* *}$ & $-0.01^{* *}$ & $0.04^{* *}$ & $0.03^{* *}$ \\
\hline Hipp & $\mathrm{L}$ & 332 & -24 & -30 & 4 & 0.12 & 0.17 & $-0.03^{* *}$ & 0.21 & $-0.07^{* *}$ & $-0.06^{* *}$ & $-0.09^{* *}$ & $0.05^{* *}$ \\
\hline SFG & $\mathrm{L}$ & 295 & -4 & 38 & 48 & 0.13 & 0.17 & $0.09 *$ & 0.22 & $0.03^{* *}$ & $0.08^{* *}$ & $0.10^{*}$ & $0.05^{* *}$ \\
\hline MTG & $\mathrm{L}$ & 292 & -66 & -16 & -30 & 0.13 & 0.16 & $0.04^{* *}$ & 0.18 & $0.07^{*}$ & $-0.003^{* *}$ & $0.10^{\mathrm{a}}$ & $-0.06^{* *}$ \\
\hline STG & $\mathrm{R}$ & 196 & 50 & -24 & 2 & 0.12 & 0.17 & $0.01^{* *}$ & 0.22 & $0.06^{* *}$ & $0.08^{* *}$ & $-0.03^{* *}$ & $-0.03^{* *}$ \\
\hline Cerebellum & $\mathrm{L}$ & 157 & -48 & -58 & -50 & 0.12 & 0.15 & $-0.03^{* *}$ & 0.19 & $0.09^{*}$ & $-0.04^{* *}$ & $0.07^{*}$ & $0.05^{* *}$ \\
\hline $\mathrm{LOC}$ & $\mathrm{L}$ & 142 & -36 & -64 & 2 & 0.12 & 0.17 & $0.08^{*}$ & 0.18 & $-0.07^{* *}$ & $-0.04^{* *}$ & $0.06^{*}$ & $0.01 * *$ \\
\hline
\end{tabular}

D, Phonological decoding; A, form-sound association; S, naming speed; M, memory ability; RT, reaction time; Hipp, hippocampus; SFG, superior frontal gyrus; MTG/STG, middle/superior temporal gyrus; LOC, lateral occipital cortex. ${ }^{* *} p<0.01,{ }^{*} p<0.05,{ }^{a} p<0.10$. Significance denotes test of prediction accuracy difference between form-sound association and other two reading components as well as measures of cognitive abilities.

$-86,-40, r=0.23, \mathrm{MNI}=-48,-58,-50, r=0.19 ;$ right: $\mathrm{MNI}=$ $36,-60,-44, r=0.22)$, bilateral hippocampus (Hipp; left: $\mathrm{MNI}=$ $-24,-30,4, r=0.21$; right: $\mathrm{MNI}=28,-30,-6, r=0.19)$, left SFG $(\mathrm{MNI}=-4,38,48, r=0.22)$, left MTG $(\mathrm{MNI}=-66,-16,-30$, $r=0.18)$, right STG $(\mathrm{MNI}=50,-24,2, r=0.22)$, and left LOC (MNI $=-36,-64,2, r=0.18)$. All correlations were positive. Prediction accuracy was significantly higher for form-sound association than for other reading components and general cognitive abilities (Table 5; Fig. 2).

In contrast, naming speed could be predicted by the GMV in a distributed occipital-temporal-parietal-frontal regions, includ- ing the bilateral LOC/PreCu (MNI $=-12,-70,34, r=0.23$ ), right inferior/middle temporal gyrus (ITG/MTG; $\mathrm{MNI}=56$, $-62,24, r=0.23)$, left superior temporal gyrus/angular gyrus (STG/AG; MNI $=-62,-30,12, r=0.21)$, right insular cortex (Ins; $\mathrm{MNI}=44,12,-4, r=0.23$ ), right temporal-parietal junction (TPJ; MNI $=56,-38,18, r=0.22$ ), right superior/middle frontal gyrus (SFG/MFG; MNI $=16,16,68, r=0.18)$, left STG $(\mathrm{MNI}=-60,-8,0, r=0.20)$, left PCC $(\mathrm{MNI}=-12,-40,4$, $r=0.20)$, right MFG $(\mathrm{MNI}=36,4,40, r=0.23)$, left ACC $(\mathrm{MNI}=-12,38,30, r=0.24)$, and left ventromedial prefrontal cortex (VMPFC; MNI $=-4,56,-12, r=0.17)$. Correlational 

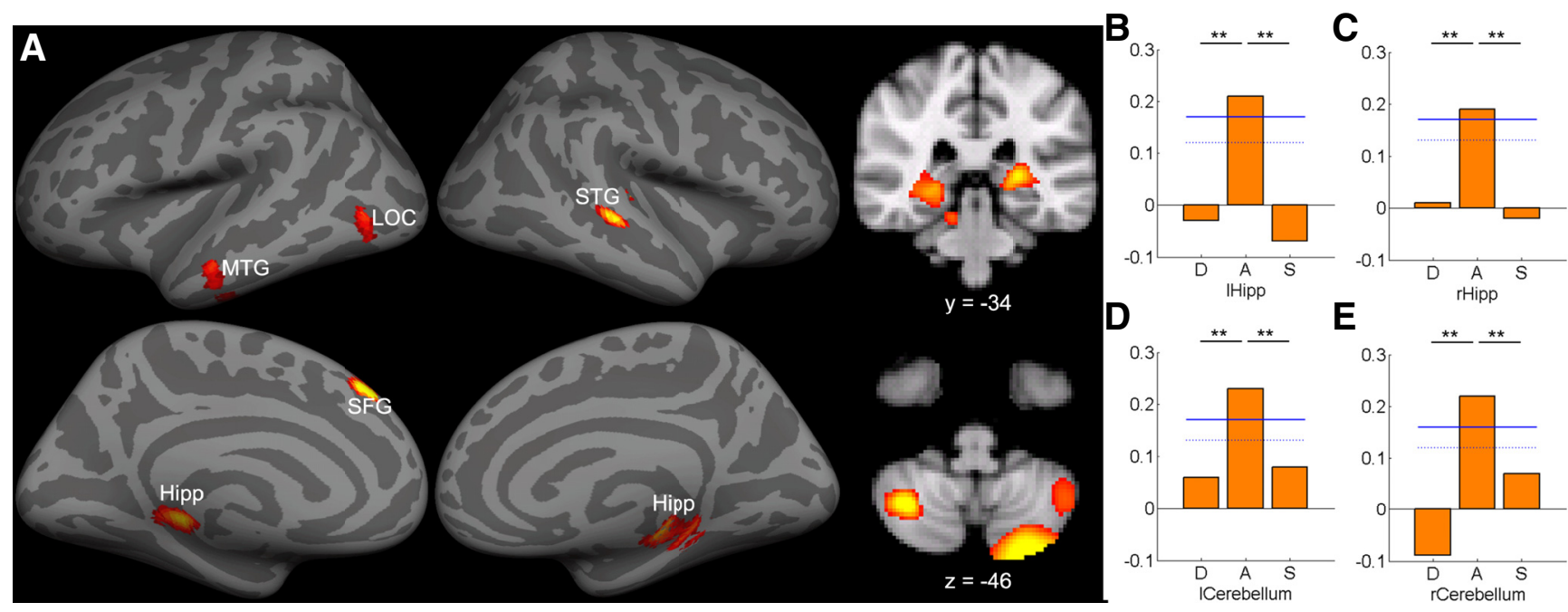

Figure 2. A, MVPA revealed significant correlations between GMV and form-sound association mapped onto to the inflated gray matter surface as well as in coronal and axial slice. The bar graphs show the prediction accuracy in four example ROls, including $(\boldsymbol{B})$ left hippocampus, $(\boldsymbol{C})$ right hippocampus, (D) left cerebellum, and $(\boldsymbol{E})$ right cerebellum. Permutation-based 95 th percentile (dotted blue line) and 99 th percentile (solid blue line) prediction accuracies are also shown $\left({ }^{* *} p<0.01\right)$. Images are reversed left to right to follow radiologic convention. See Table 5 for ROI abbreviations.

Table 6. Brain regions showing significant correlations between GMV and naming speed in MVPA analysis

\begin{tabular}{|c|c|c|c|c|c|c|c|c|c|c|c|c|c|}
\hline \multirow[b]{2}{*}{ Brain Regions } & \multirow[b]{2}{*}{$L / R$} & \multirow[b]{2}{*}{ No. Voxels } & \multicolumn{3}{|c|}{ MNI Coordinates } & \multirow[b]{2}{*}{$95 \%$} & \multirow[b]{2}{*}{$99 \%$} & \multicolumn{6}{|c|}{ Prediction Accuracy } \\
\hline & & & $x$ & $y$ & $z$ & & & D & A & $S$ & IQ & M & RT \\
\hline LOC/PreCu & $L / R$ & 1276 & -12 & -70 & 34 & 0.12 & 0.17 & $0.02^{* *}$ & $0.01^{* *}$ & 0.23 & $0.11^{*}$ & $-0.02^{* *}$ & $-0.01^{* *}$ \\
\hline ITG/MTG & $\mathrm{R}$ & 999 & 56 & -62 & -24 & 0.13 & 0.17 & $0.02^{* *}$ & $-0.05^{* *}$ & 0.23 & $0.11^{*}$ & $0.08^{* *}$ & $-0.06^{* *}$ \\
\hline STG/AG & L & 875 & -62 & -30 & 12 & 0.13 & 0.17 & $-0.03^{* *}$ & $0.03^{* *}$ & 0.21 & $0.06^{* *}$ & $0.01^{* *}$ & $0.06^{* *}$ \\
\hline Ins & $\mathrm{R}$ & 626 & 44 & 12 & -4 & 0.13 & 0.17 & $-0.02^{* *}$ & $0.02^{* *}$ & 0.23 & $0.03^{* *}$ & $0.06^{* *}$ & $-0.03^{* *}$ \\
\hline TPJ & $\mathrm{R}$ & 352 & 56 & -38 & 18 & 0.12 & 0.16 & $0.04^{* *}$ & $0.03^{* *}$ & 0.22 & $0.07^{* *}$ & $-0.07^{* *}$ & $0.08^{* *}$ \\
\hline SFG/MFG & $\mathrm{R}$ & 340 & 16 & 16 & 68 & 0.12 & 0.16 & $-0.04^{* *}$ & $-0.08^{* *}$ & 0.18 & $0.11^{\mathrm{ns}}$ & $0.09^{a}$ & $0.08^{*}$ \\
\hline STG & L & 303 & -60 & -8 & 0 & 0.13 & 0.16 & $-0.07^{* *}$ & $-0.01^{* *}$ & 0.20 & $0.09^{*}$ & $0.04^{* *}$ & $-0.03^{* *}$ \\
\hline $\mathrm{PCC}$ & L & 263 & -12 & -40 & 4 & 0.14 & 0.18 & $0.002^{* *}$ & $-0.01^{* *}$ & 0.20 & $0.02^{* *}$ & $-0.05^{* *}$ & $0.12^{\mathrm{a}}$ \\
\hline MFG & $\mathrm{R}$ & 199 & 36 & 4 & 40 & 0.12 & 0.17 & $0.03^{* *}$ & $0.06^{* *}$ & 0.22 & $0.01^{* *}$ & $0.07^{* *}$ & $0.13^{\mathrm{a}}$ \\
\hline $\mathrm{ACC}$ & L & 176 & -12 & 38 & 30 & 0.12 & 0.16 & $-0.04^{* *}$ & $-0.08^{* *}$ & 0.24 & $0.10^{*}$ & $0.02^{* *}$ & $0.005^{* *}$ \\
\hline VMPFC & L & 176 & -4 & 56 & -12 & 0.13 & 0.16 & $-0.001^{* *}$ & $0.04^{*}$ & 0.17 & $0.15^{\mathrm{ns}}$ & $-0.09^{* *}$ & $0.13^{\mathrm{ns}}$ \\
\hline
\end{tabular}

D, Phonological decoding; A, form-sound association; S, naming speed; M, memory ability; RT, reaction time; LOC, lateral occipital cortex; PreCu, precuneus; ITG/MTG/STG, inferior/middle/superior temporal gyrus; AG, angular gyrus; Ins, insula; TPJ, temporal-parietal junction; SFG/MFG, superior/middle frontal gyrus; PCC, posterior cingulate cortex; ACC, anterior cingulate cortex; VMPFC, ventromedial prefrontal cortex.

${ }^{* *} p<0.01,{ }^{*} p<0.05,{ }^{a} p<0.10,{ }^{\text {ns }} p>0.10$. Significance denotes test of prediction accuracy difference between naming speed and other two reading components as well as measures of cognitive abilities.

analysis suggested that all correlations were positive. In all these regions, prediction accuracy was significantly higher for naming speed than for phonological decoding or form-sound association (Table 6; Fig. 3).

Consistent with the results that naming speed was significantly correlated with IQ and reaction time, some of these regions that could predict naming speed could also (marginally) significantly predict general IQ (right SFG/MFG and left VMPFC) and reaction time (left PCC, right MFG and left VMPFC; Table 6).

\section{Univariate results}

Table 7 summarizes findings on brain regions that showed positive or negative correlations between GMV and the three components of reading abilities in univariate VBM analysis. In particular, phonological decoding was positively correlated with GMV in the left SPL/ SMG (Fig. 4A; Table 7; MNI $=-30,-38,42, Z=4.35$ ), but negatively correlated with GMV in the left PCC/PreCu $(\mathrm{MNI}=-6$, $-52,24, Z=4.43$ ). The GMV in these two regions was more highly correlated with phonological decoding than with naming speed (both $Z>2.90, p<0.01$ ) or form-sound association (both $Z>2.21$, $p<0.05)$.

Form-sound association was positively correlated with GMV in the bilateral hippocampus (Fig. 4B; Table 7; left: $\mathrm{MNI}=-28$, $-32,-6, Z=3.98$; right: $\mathrm{MNI}=24,-36,4, Z=4.39)$, right $\mathrm{SFG}$
$(\mathrm{MNI}=4,36,48, Z=4.20)$, and left $\mathrm{AG}(\mathrm{MNI}=-56,-50,20$, $Z=3.94)$. No negative correlation was found between GMV and form-sound association. The GMV in these regions was more highly correlated with form-sound association than with phonological decoding (all $Z>1.72, p<0.05$ ) or naming speed (all $Z>$ $1.83, p<0.05)$.

Naming speed was positively correlated with GMV in several brain regions (Fig. 4C; Table 7), including the right insular cortex $(\mathrm{MNI}=44,12,-6, Z=4.12)$, right $\mathrm{TPJ}(\mathrm{MNI}=56,-38,16$, $Z=3.73)$, right $\mathrm{MFG}(\mathrm{MNI}=36,6,38, Z=3.60)$, left ACC $(\mathrm{MNI}=-8,40,28, Z=4.36)$, and left PCC/PreCu $(\mathrm{MNI}=-10$, $-66,34, Z=3.80$ ), whereas no brain regions showed negative correlation between GMV and naming speed. The GMV in these regions was more highly correlated with naming speed than with phonological decoding (all $Z>2.05, p<0.05$ ) or form-sound association (all $Z>1.72, p<0.05$ ).

\section{Discussion}

Although a multicomponential view of reading ability has been widely accepted in cognitive research of reading and reading difficulties (e.g., dyslexia, Norton and Wolf, 2012), few studies have examined the neuroanatomic basis of these components. To fill this gap, the present study administered several reading tasks to a 

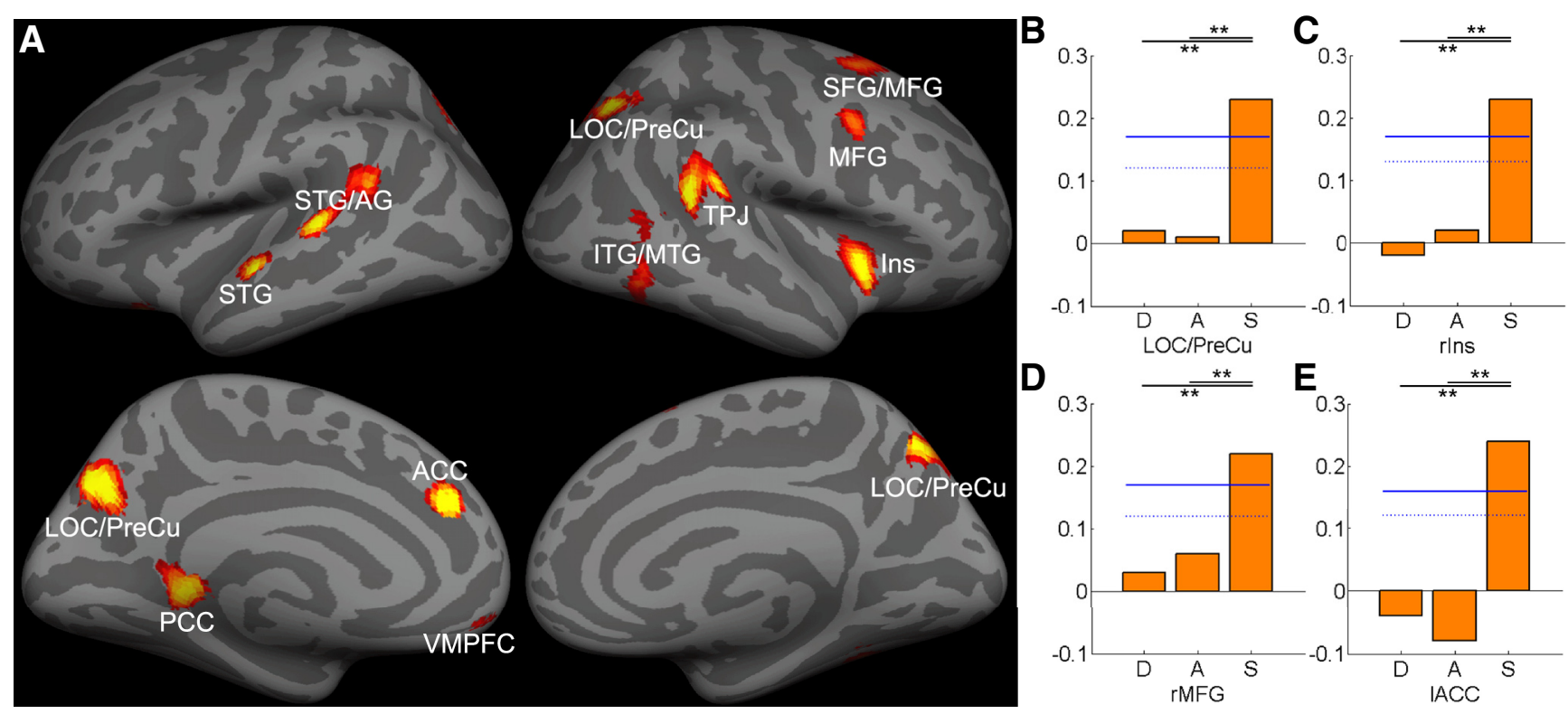

Figure 3. A, MVPA revealed significant correlations between GMV and naming speed mapped onto to the inflated gray matter surface. The bar graphs show the prediction accuracy in four ROls, including $(\boldsymbol{B})$ LOC/PreCu, $(\boldsymbol{C})$ right insula, (D) right MFG, and (E) left ACC. Permutation-based 95th percentile (dotted blue line) and 99th percentile (solid blue line) prediction accuracies are also shown $\left.{ }^{* *} p<0.01\right)$. See Table 6 for ROl abbreviations.

Table 7. Brain regions showing significant correlations between GMV and reading abilities in univariate VBM analysis

\begin{tabular}{|c|c|c|c|c|c|c|c|c|c|c|}
\hline & \multirow[b]{2}{*}{ Brain Regions } & \multirow[b]{2}{*}{$L / R$} & \multirow[b]{2}{*}{ No. Voxels } & \multicolumn{3}{|c|}{ MNI Coordinates } & \multirow[b]{2}{*}{$Z$} & \multicolumn{3}{|c|}{ Person's $r$} \\
\hline & & & & $x$ & $y$ & $z$ & & D & A & $S$ \\
\hline \multicolumn{11}{|c|}{ Phonological decoding } \\
\hline Positive & SPL/SMG & L & 45 & -30 & -38 & 42 & 4.35 & 0.24 & -0.10 & -0.01 \\
\hline Negative & PCC/PreCu & $\mathrm{L}$ & 193 & -6 & -52 & 24 & 4.43 & -0.28 & -0.09 & -0.02 \\
\hline \multicolumn{11}{|c|}{ Form-sound association } \\
\hline \multirow[t]{4}{*}{ Positive } & Hipp & $\mathrm{R}$ & 40 & 24 & -36 & 4 & 4.39 & -0.02 & 0.25 & -0.06 \\
\hline & SFG & $\mathrm{R}$ & 75 & 4 & 36 & 48 & 4.20 & 0.08 & 0.23 & 0.06 \\
\hline & Hipp & $\mathrm{L}$ & 104 & -28 & -32 & -6 & 3.98 & 0.07 & 0.23 & 0.003 \\
\hline & $A G$ & L & 34 & -56 & -50 & 20 & 3.94 & -0.08 & 0.23 & 0.07 \\
\hline Negative & NONE & & & & & & & & & \\
\hline \multicolumn{11}{|c|}{ Naming speed } \\
\hline \multirow[t]{5}{*}{ Positive } & Ins & $\mathrm{R}$ & 69 & 44 & 12 & -6 & 4.12 & 0.03 & 0.04 & 0.24 \\
\hline & TPJ & $\mathrm{R}$ & 33 & 56 & -38 & 16 & 3.73 & -0.04 & 0.02 & 0.22 \\
\hline & MFG & $\mathrm{R}$ & 33 & 36 & 6 & 38 & 3.60 & 0.04 & 0.02 & 0.22 \\
\hline & $\mathrm{ACC}$ & $\mathrm{L}$ & 54 & -8 & 40 & 28 & 4.36 & -0.01 & -0.01 & 0.26 \\
\hline & PCC/PreCu & $\mathrm{L}$ & 52 & -10 & -66 & 34 & 3.80 & -0.03 & 0.01 & 0.23 \\
\hline Negative & NONE & & & & & & & & & \\
\hline
\end{tabular}

SPL, Superior parietal lobe; SMG, supramarginal gyrus; PCC, posterior cingulate cortex; PreCu, precuneus; Hipp, hippocampus; M/SFG, middle/superior frontal gyrus; AG, angular gyrus; Ins, insula; TPJ, temporal-parietal junction; ACC, anterio cingulate cortex.

large sample of participants and identified three uncorrelated components of reading ability: phonological decoding, formsound association, and naming speed. Using a multivariate predictive decoding method, we found that the GMV in distinct neural regions were correlated with the three components of reading ability.

Phonological decoding refers to the procedure of extracting phonology from printed words, which is a critical component in early reading development (Hamada and Koda, 2008) and a reliable predictor of reading success (Wagner et al., 1994). Growing literature has posited the left SMG in phonological decoding. For example, neuroimaging studies have consistently revealed SMG activation during phonological processing of written words, especially pseudowords, when the application of grapheme-tophoneme correspondence is required (Tan et al., 2005; Richlan et al., 2009). Transcranial magnetic stimulation applied over the SMG could selectively disrupt phonological decoding (Hartwig- sen et al., 2010). Not only were subjects with dyslexia found to show functional and structural impairment in this region (Richlan et al., 2009), the functional (Welcome and Joanisse, 2012) and anatomical (Lee et al., 2007; Goldman and Manis, 2013) variations in this region could also account for individual differences in reading performance among typical readers.

The brain region whose GMV was correlated with phonological decoding in the present study was located in the SPL that extended to the SMG. As participants in the current study were native Chinese speakers who were learning English as a second language, our result might reflect cultural differences in reading and the role of native language experiences in shaping the neural substrates of second language reading (Tan et al., 2003; Chen et al., 2009). Chinese and English, based on two different writing systems, rely on partially distinct neural substrates (Tan et al., 2005; Chen et al., 2009). Specifically, Chinese is a logographic writing system in which each character maps on a morpheme, 


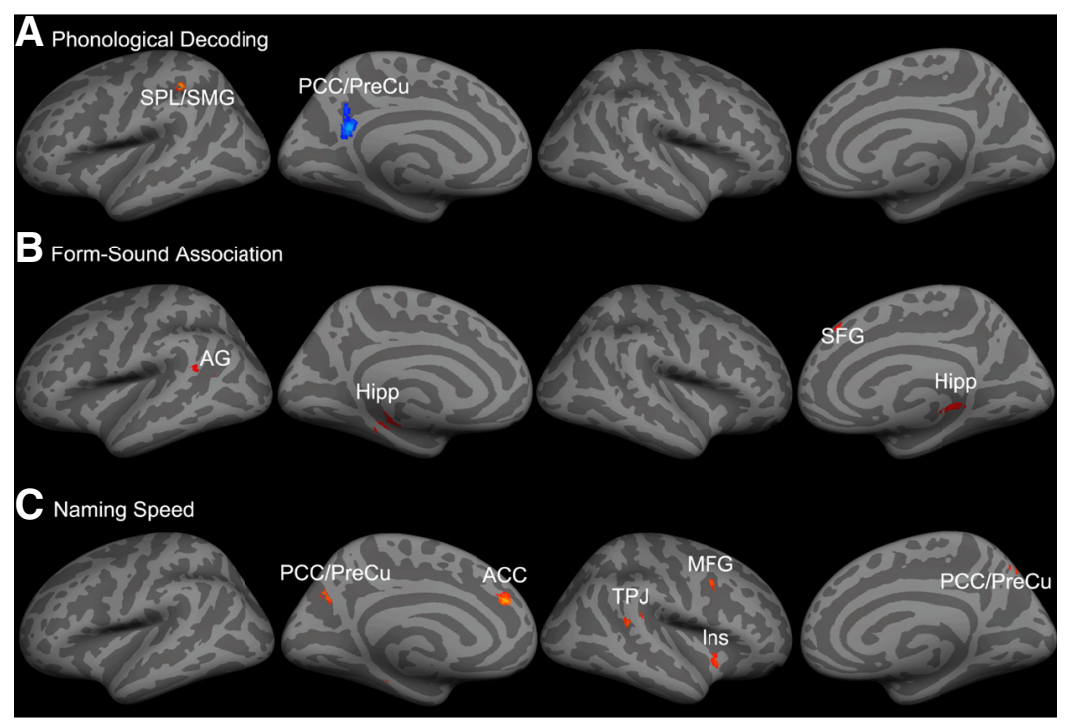

Figure 4. A, Univariate VBM results showed significant correlations between GMV and phonological decoding mapped onto gray matter surface. GMV in left SPL/SMG (in red) was positively correlated with phonological decoding, whereas GMV in left PCC/PreCu (in blue) was negatively correlated with phonological decoding. $\boldsymbol{B}$, Univariate VBM results showed significant correlations between GMV and form-sound association mapped onto gray matter surface. GMV in bilateral hippocampus, left AG and right SFG were positively correlated with form-sound association. C, Univariate VBM results showed significant correlations between GMV and naming speed mapped onto gray matter surface. GMV in the PCC/PreCu, left ACC, right TPJ, right MFG and right insula were positively correlated with naming speed. See Table 7 for abbreviations.

and the sublexical reading or grapheme-phoneme correspondence rule is impossible. As a result, Chinese reading relies more on the SPL than the SMG (Tan et al., 2005). Furthermore, native language experience may shape the neural strategy of second language learning such that the SPL showed strong activation when Chinese readers were reading English (Tan et al., 2003). Our structure-function correlation results are consistent with this observation.

Form-sound association refers to the ability to make connections between a new morpheme and sound, thus is critical to both learning and reading (Manis et al., 1987). Not surprisingly, the regions that are predictive of this ability, particularly the hippocampus, have been consistently implicated in language learning and general memory tasks. For example, the hippocampus has also been implicated in learning new lexicons (Breitenstein et al., 2005; Davis et al., 2009), and the integrity of the hippocampus and surrounding white matter is correlated with language training success in aphasia (Meinzer et al., 2010). On the other hand, studies on patients with hippocampal lesions (e.g., patient HM Corkin, 2002) and neuroimaging studies on healthy participants (Schacter and Wagner, 1999; Eldridge et al., 2000; Greicius et al., 2002; Zeineh et al., 2003) have all emphasized the role of the hippocampus in memory encoding and retrieval. These observations are quite consistent with the idea that the declarative memory system supported by the medial temporal cortex plays an important role in lexicons (Ullman, 2004). The low prediction accuracy between the hippocampus GMV and item memory is also consistent with the finding that the hippocampus is particularly important for associative memory rather than for item memory (Eichenbaum, 2004; Giovanello et al., 2004; Mayes et al., 2007).

Although rapid automatized naming (RAN) has been found to predict reading across a large life span, its neural correlates have been poorly understood (Norton and Wolf, 2012). The only published study found a distributed brain region, including the inferior frontal cortex, temporoparietal junction, and the ventral visual stream, for rapid naming of letters and objects (Misra et al., 2004). RAN performance was correlated with activation in several frontal and temporal regions during an implicit reading task (Turkeltaub et al., 2003) and the brain volume in the cerebellum and pars triangularis (Eckert et al., 2003). Our results are in general agreement with these observations by revealing that the GMV in a distributed neural network could predict naming speed.

More interestingly, our results suggest that naming speed is associated with general intelligence and reaction time, which is consistent with the tight relationship between reaction time and intelligence (Jensen and Munro, 1979; Fry and Hale, 2000). Although a close examination of the anatomical basis of processing speed and intelligence is beyond the scope of this study, we did find that some of the regions that were predictive of naming speed also predicted intelligence and processing speed. Consistently, functional MRI studies have suggested that a distributed brain network subserves processing speed, including the prefrontal, occipital, temporal, and parietal cortices (for review, see Deary et al., 2010). Both white matter volume and GMV in those regions were also associated with processing speed (Kochunov et al., 2010); age-related processing speed decline was associated with decreased gray matter density in the prefrontal regions, temporal lobe, and posterior parietal cortex (Tisserand et al., 2004).

Our results provide solid evidence for multiple components of reading ability that are supported by distinct cognitive and neural mechanisms. Furthermore, these abilities are at least partially independent from general processing abilities, such as episodic memory and processing speed. This is not to say that these processes and the supporting neural structures are exclusive for reading, as there is no doubt that reading must be built upon some general cognitive functions. For example, our observation that RAN is moderately correlated with general intelligence and processing speed, and they are supported by partially overlapping neural mechanisms is consistent with many previous studies (Kail and Hall, 1994; Catts et al., 2002; Powell et al., 2007). Nevertheless, RAN made additional contribution to reading after controlling for general processing speed (Cutting and Denckla, 2001; Powell et al., 2007), suggesting that RAN builds on the existing architecture for more general speeded processing to support automatic form-sound associations (Wolf and Bowers, 1999). Similarly, the SPL/SMG and the hippocampus play many functions in addition to reading. The lack of correlation, for example, between form-sound association and memory certainly can be due to the specific memory task we chose. However, many years' experience of reading might have finely tuned these systems to meet the special requirement of reading, like applying grapheme-phoneme correspondence rule and building the word form and sound association, and thus form a special microanatomical pattern for reading (Dehaene and Cohen, 2007). By dissociating or associating reading with other general cognitive abilities, our method could potentially contribute to a deeper understanding of the nature of reading ability and reading diffi- 
culties, especially when combined with methods that can identify finer functional segregations within a brain region (Fedorenko et al., 2010).

VBM is relatively fast and automated, yet sensitive to the morphological change in gray matter (Good et al., 2001). These advantages make it suitable for studies with large samples. However, as suggested by Mechelli et al. (2005), the GMV measured by VBM could be contributed by changes in neuronal size, dendritic or axonal arborization, cortical folding, or cortical thickness. How these micro anatomical changes affect behavior is barely understood. In addition, our results could not pinpoint whether the observed correlations were caused by preexisting individual differences (Xue et al., 2006b; Wong et al., 2011) or brain plasticity during language learning (Mechelli et al., 2004; Carreiras et al., 2009). Future longitudinal studies might help to address this issue (Hoeft et al., 2011).

Recently, multivariate pattern analysis has gained increasing attention in the neuroimaging field (Norman et al., 2006). Beyond categorizing objective processing and mental states, emerging studies have used this method to decode continuous variables (Dosenbach et al., 2010; Cohen et al., 2011). Direct comparison between univariate and multivariate analyses suggests that although both methods identify similar regions and the MVPA method was in general more sensitive than the univariate methods, these two methods did also capture different aspects of the data (Jimura and Poldrack, 2012). The searchlight method used in the current study aimed to provide finer structure-function associations, but did not answer the question as to how accurately one can read out an individual's reading ability when all the anatomical data are aggregated. Our results could provide important prior knowledge to facilitate feature selection and to improve accuracy in future research.

In summary, our results suggest that reading ability consists of multiple components that are related to the anatomical structure in distinct brain regions. These results shed light on the important relationship between brain structure and function, and can be leveraged to understand individual differences among populations with typical and atypical reading development.

\section{References}

Blackmon K, Barr WB, Kuzniecky R, Dubois J, Carlson C, Quinn BT, Blumberg M, Halgren E, Hagler DJ, Mikhly M, Devinsky O, McDonald CR, Dale AM, Thesen T (2010) Phonetically irregular word pronunciation and cortical thickness in the adult brain. Neuroimage 51:1453-1458. CrossRef Medline

Blackmon K, Halgren E, Barr WB, Carlson C, Devinsky O, DuBois J, Quinn BT, French J, Kuzniecky R, Thesen T (2011) Individual differences in verbal abilities associated with regional blurring of the left gray and white matter boundary. J Neurosci 31:15257-15263. CrossRef Medline

Breitenstein C, Jansen A, Deppe M, Foerster AF, Sommer J, Wolbers T, Knecht S (2005) Hippocampus activity differentiates good from poor learners of a novel lexicon. Neuroimage 25:958-968. CrossRef Medline

Brem S, Bach S, Kucian K, Guttorm TK, Martin E, Lyytinen H, Brandeis D, Richardson U (2010) Brain sensitivity to print emerges when children learn letter-speech sound correspondences. Proc Natl Acad Sci U S A 107:7939-7944. CrossRef Medline

Carreiras M, Seghier ML, Baquero S, Estévez A, Lozano A, Devlin JT, Price CJ (2009) An anatomical signature for literacy. Nature 461:983-986. CrossRef Medline

Catts HW, Fey ME, Tomblin JB, Zhang X (2002) A longitudinal investigation of reading outcomes in children with language impairments. J Speech Lang Hear Res 45:1142-1157. CrossRef Medline

Chen C, Xue G, Mei L, Dong Q (2009) Cultural neurolinguistics. Prog Bain Res 178:159-171. CrossRef Medline

Cohen JR, Asarnow RF, Sabb FW, Bilder RM, Bookheimer SY, Knowlton BJ, Poldrack RA (2011) Decoding continuous variables from neuroimaging data: basic and clinical applications. Front Neurosci 5:75. CrossRef Medline

Corkin S (2002) What's new with the amnesic patient HM? Nat Rev Neurosci 3:153-160. CrossRef Medline

Cutting LE, Denckla MB (2001) The relationship of rapid serial naming and word reading in normally developing readers: an exploratory model. Read Writ 14:673-705. CrossRef

Davis MH, Di Betta AM, Macdonald MJ, Gaskell MG (2009) Learning and consolidation of novel spoken words. J Cogn Neurosci 21:803-820. CrossRef Medline

Deary IJ, Penke L, Johnson W (2010) The neuroscience of human intelligence differences. Nat Rev Neurosci 11:201-211. CrossRef Medline

Dehaene S, Cohen L (2007) Cultural recycling of cortical maps. Neuron 56:384-398. CrossRef Medline

Dehaene S, Pegado F, Braga LW, Ventura P, Nunes Filho G, Jobert A, Dehaene-Lambertz G, Kolinsky R, Morais J, Cohen L (2010) How learning to read changes the cortical networks for vision and language. Science 330:1359-1364. CrossRef Medline

Dosenbach NU, Nardos B, Cohen AL, Fair DA, Power JD, Church JA, Nelson SM, Wig GS, Vogel AC, Lessov-Schlaggar CN, Barnes KA, Dubis JW, Feczko E, Coalson RS, Pruett JR Jr, Barch DM, Petersen SE, Schlaggar BL (2010) Prediction of individual brain maturity using fMRI. Science 329: 1358-1361. CrossRef Medline

Drucker H, Burges CJC, Kaufman L, Smola A, Vapnik V (1997) Support vector regression machines. In: Advances in neural information processing system, Vol 9 (Mozer M, Jordan M, Petsche T, eds), pp 155-161. MIT: Cambridge, $M A$.

Eckert MA, Leonard CM, Richards TL, Aylward EH, Thomson J, Berninger VW (2003) Anatomical correlates of dyslexia: frontal and cerebellar findings. Brain 126:482-494. CrossRef Medline

Eichenbaum H (2004) Hippocampus: cognitive processes and neural representations that underlie declarative memory. Neuron 44:109-120. CrossRef Medline

Eldridge LL, Knowlton BJ, Furmanski CS, Bookheimer SY, Engel SA (2000) Remembering episodes: a selective role for the hippocampus during retrieval. Nat Neurosci 3:1149-1152. CrossRef Medline

Fedorenko E, Hsieh PJ, Nieto-Castañón A, Whitfield-Gabrieli S, Kanwisher N (2010) New method for fMRI investigations of language: defining ROIs functionally in individual subjects. J Neurophysiol 104:1177-1194. CrossRef Medline

Fiez JA, Petersen SE (1998) Neuroimaging studies of word reading. Proc Natl Acad Sci U S A 95:914-921. CrossRef Medline

Fry AF, Hale S (2000) Relationships among processing speed, working memory, and fluid intelligence in children. Biol Psychol 54:1-34. CrossRef Medline

Frye RE, Liederman J, Malmberg B, McLean J, Strickland D, Beauchamp MS (2010) Surface area accounts for the relation of gray matter volume to reading-related skills and history of dyslexia. Cereb Cortex 20:2625-2635. CrossRef Medline

Goldman JG, Manis FR (2013) Relationships among cortical thickness, reading skill, and print exposure in adults. Sci Stud Read 17:163-176. CrossRef

Good CD, Johnsrude IS, Ashburner J, Henson RN, Friston KJ, Frackowiak RS (2001) A voxel-based morphometric study of ageing in 465 normal adult human brains. Neuroimage 14:21-36. CrossRef Medline

Greicius MD, Krasnow B, Boyett-Anderson JM, Eliez S, Schatzberg AF, Reiss AL, Menon V (2003) Regional analysis of hippocampal activation during memory encoding and retrieval: fMRI study. Hippocampus 13:164174. CrossRef Medline

Hamada M, Koda K (2008) Influence of first language orthographic experience on second language decoding and word learning. Lang Learn 58:1-31. CrossRef

Hanke M, Halchenko YO, Sederberg PB, Hanson SJ, Haxby JV, Pollmann S (2009) PyMVPA: a python toolbox for multivariate pattern analysis of fMRI data. Neuroinformatics 7:37-53. CrossRef Medline

Hartwigsen G, Baumgaertner A, Price CJ, Koehnke M, Ulmer S, Siebner HR (2010) Phonological decisions require both the left and right supramarginal gyri. Proc Natl Acad Sci U S A 107:16494-16499. CrossRef Medline

He Q, Xue G, Chen C, Lu Z, Dong Q, Lei X, Ding N, Li J, Li H, Chen C, Li J, Moyzis RK, Bechara A (2010) Serotonin transporter gene-linked polymorphic region (5-HTTLPR) influences decision making under ambigu- 
ity and risk in a large Chinese sample. Neuropharmacology 59:518-526. CrossRef Medline

He Q, Xue G, Chen C, Lu ZL, Lei X, Liu Y, Li J, Zhu B, Moyzis RK, Dong Q, Bechara A (2012) COMT Val158Met polymorphism interacts with stressful life events and parental warmth to influence decision making. Sci Rep 2:677. CrossRef Medline

Hoeft F, Meyler A, Hernandez A, Juel C, Taylor-Hill H, Martindale JL, McMillon G, Kolchugina G, Black JM, Faizi A, Deutsch GK, Siok WT, Reiss AL, Whitfield-Gabrieli S, Gabrieli JD (2007) Functional and morphometric brain dissociation between dyslexia and reading ability. Proc Natl Acad Sci U S A 104:4234-4239. CrossRef Medline

Hoeft F, McCandliss BD, Black JM, Gantman A, Zakerani N, Hulme C, Lyytinen H, Whitfield-Gabrieli S, Glover GH, Reiss AL, Gabrieli JD (2011) Neural systems predicting long-term outcome in dyslexia. Proc Natl Acad Sci U S A 108:361-366. CrossRef Medline

Hoover WA, Gough PB (1990) The simple view of reading. Read Writ 2:127-160. CrossRef

Jensen AR, Munro E (1979) Reaction time, movement time, and intelligence. Intelligence 3:121-126. CrossRef

Jimura K, Poldrack RA (2012) Analyses of regional-average activation and multivoxel pattern information tell complementary stories. Neuropsychologia 50:544-552. CrossRef Medline

Joshi RM, Aaron P (2000) The component model of reading: simple view of reading made a little more complex. Read Psychol 21:85-97. CrossRef

Kail R, Hall LK (1994) Processing speed, naming speed, and reading. Dev Psychol 30:949. CrossRef

Kochunov P, Coyle T, Lancaster J, Robin DA, Hardies J, Kochunov V, Bartzokis G, Stanley J, Royall D, Schlosser AE, Null M, Fox PT (2010) Processing speed is correlated with cerebral health markers in the frontal lobes as quantified by neuroimaging. Neuroimage 49:1190-1199. CrossRef Medline

Kriegeskorte N, Goebel R, Bandettini P (2006) Information-based functional brain mapping. Proc Natl Acad Sci U S A 103:3863-3868. CrossRef Medline

Lee H, Devlin JT, Shakeshaft C, Stewart LH, Brennan A, Glensman J, Pitcher K, Crinion J, Mechelli A, Frackowiak RS, Green DW, Price CJ (2007) Anatomical traces of vocabulary acquisition in the adolescent brain. J Neurosci 27:1184-1189. CrossRef Medline

Linkersdörfer J, Lonnemann J, Lindberg S, Hasselhorn M, Fiebach CJ (2012) Grey matter alterations colocalize with functional abnormalities in developmental dyslexia: an ALE meta-analysis. PLoS One 7:e43122. CrossRef Medline

Liu Y, Shu H, Li P (2007) Word naming and psycholinguistic norms: Chinese. Behav Res Methods 39:192-198. CrossRef Medline

Manis FR, Savage PL, Morrison FJ, Horn CC, Howell MJ, Szeszulski PA, Holt LK (1987) Paired associate learning in reading-disabled children: evidence for a rule-learning deficiency. J Exp Child Psychol 43:25-43. CrossRef Medline

Mayes A, Montaldi D, Migo E (2007) Associative memory and the medial temporal lobes. Trends Cogn Sci 11:126-135. CrossRef Medline

McCandliss BD, Cohen L, Dehaene S (2003) The visual word form area: expertise for reading in the fusiform gyrus. Trends Cogn Sci 7:293-299. CrossRef Medline

Mechelli A, Crinion JT, Noppeney U, O’Doherty J, Ashburner J, Frackowiak RS, Price CJ (2004) Neurolinguistics: structural plasticity in the bilingual brain. Nature 431:757. CrossRef Medline

Mechelli A, Price CJ, Friston KJ, Ashburner J (2005) Voxel-based morphometry of the human brain: methods and applications. Curr Med Image Rev 1:105-113. CrossRef

Meinzer M, Mohammadi S, Kugel H, Schiffbauer H, Flöel A, Albers J, Kramer K, Menke R, Baumgärtner A, Knecht S, Breitenstein C, Deppe M (2010) Integrity of the hippocampus and surrounding white matter is correlated with language training success in aphasia. Neuroimage 53:283-290. CrossRef Medline

Misra M, Katzir T, Wolf M, Poldrack RA (2004) Neural systems for rapid automatized naming in skilled readers: unraveling the RAN-reading relationship. Sci Stud Read 8:241-256. CrossRef

Nichols TE, Holmes AP (2002) Nonparametric permutation tests for functional neuroimaging: a primer with examples. Hum Brain Mapp 15:1-25. CrossRef Medline

Norman KA, Polyn SM, Detre GJ, Haxby JV (2006) Beyond mind-reading: multi-voxel pattern analysis of fMRI data. Trends Cogn Sci 10:424-430. CrossRef Medline

Norton ES, Wolf M (2012) Rapid automatized naming (RAN) and reading fluency: implications for understanding and treatment of reading disabilities. Annu Rev Psychol 63:427-452. CrossRef Medline

Powell D, Stainthorp R, Stuart M, Garwood H, Quinlan P (2007) An experimental comparison between rival theories of rapid automatized naming performance and its relationship to reading. J Exp Child Psychol 98:4668. CrossRef Medline

Price CJ (2012) A review and synthesis of the first 20 years of PET and fMRI studies of heard speech, spoken language and reading. Neuroimage 62: 816-847. CrossRef Medline

Richlan F, Kronbichler M, Wimmer H (2009) Functional abnormalities in the dyslexic brain: A quantitative meta-analysis of neuroimaging studies. Hum Brain Mapp 30:3299-3308. CrossRef Medline

Richlan F, Kronbichler M, Wimmer H (2013) Structural abnormalities in the dyslexic brain: a meta-analysis of voxel-based morphometry studies. Hum Brain Mapp, in press. Retrieved July 12, 2013. doi:10.1002/hbm.22127. CrossRef Medline

Schacter DL, Wagner AD (1999) Medial temporal lobe activations in fMRI and PET studies of episodic encoding and retrieval. Hippocampus 9:7-24. CrossRef Medline

Schlaggar BL, McCandliss BD (2007) Development of neural systems for reading. Annu Rev Neurosci 30:475-503. CrossRef Medline

Schlaggar BL, Brown TT, Lugar HM, Visscher KM, Miezin FM, Petersen SE (2002) Functional neuroanatomical differences between adults and schoolage children in the processing of single words. Science 296:1476-1479. CrossRef Medline

Snyder PJ, Harris LJ (1993) Handedness, sex, and familial sinistrality effects on spatial tasks. Cortex 29:115-134. Medline

Giovanello KS, Schnyer DM, Verfaellie M (2004) A critical role for the anterior hippocampus in relational memory: evidence from an fMRI study comparing associative and item recognition. Hippocampus 14:5-8. CrossRef Medline

Tan LH, Spinks JA, Feng CM, Siok WT, Perfetti CA, Xiong J, Fox PT, Gao JH (2003) Neural systems of second language reading are shaped by native language. Hum Brain Mapp 18:158-166. CrossRef Medline

Tan LH, Laird AR, Li K, Fox PT (2005) Neuroanatomical correlates of phonological processing of Chinese characters and alphabetic words: a metaanalysis. Hum Brain Mapp 25:83-91. CrossRef Medline

Tisserand DJ, van Boxtel MP, Pruessner JC, Hofman P, Evans AC, Jolles J (2004) A voxel-based morphometric study to determine individual differences in gray matter density associated with age and cognitive change over time. Cereb Cortex 14:966-973. CrossRef Medline

Torgesen JK, Wagner RK, Rashotte CA (1999) Test of word reading efficiency (TOWRE). Austin, TX: Pro-Ed.

Turkeltaub PE, Gareau L, Flowers DL, Zeffiro TA, Eden GF (2003) Development of neural mechanisms for reading. Nat Neurosci 6:767-773. CrossRef Medline

Ullman MT (2004) Contributions of memory circuits to language: the declarative/procedural model. Cognition 92:231-270. CrossRef Medline

Vinckenbosch E, Robichon F, Eliez S (2005) Gray matter alteration in dyslexia: converging evidence from volumetric and voxel-by-voxel MRI analyses. Neuropsychologia 43:324-331. CrossRef Medline

Vul E, Harris C, Winkielman P, Pashler H (2009) Puzzlingly high correlations in fMRI studies of emotion, personality, and social cognition. Perspect Psychol Sci 4:274-290. CrossRef

Wagner RK, Torgesen JK, Rashotte CA (1994) Development of readingrelated phonological processing abilities: new evidence of bidirectional causality from a latent variable longitudinal study. Dev Psychol 30:73. CrossRef

Wagner RK, Torgesen JK, Rashotte CA (1999) Comprehensive test of phonological processing. Austin, TX: Pro-Ed.

Welcome SE, Joanisse MF (2012) Individual differences in skilled adult readers reveal dissociable patterns of neural activity associated with component processes of reading. Brain Lang 120:360-371. CrossRef Medline

Welcome SE, Chiarello C, Thompson PM, Sowell ER (2011) Reading skill is related to individual differences in brain structure in college students. Hum Brain Mapp 32:1194-1205. CrossRef Medline

Wolf M, Bowers PG (1999) The double-deficit hypothesis for the developmental dyslexias. J Educ Psychol 91:415. CrossRef

Wong FC, Chandrasekaran B, Garibaldi K, Wong PC (2011) White matter 
anisotropy in the ventral language pathway predicts sound-to-word learning success. J Neurosci 31:8780-8785. CrossRef Medline

Woodcock RN (1997) Woodcock reading mastery tests: revised/normative update. Circle Pines, MN: American Guidance Service.

Xue G, Poldrack RA (2007) The neural substrates of visual perceptual learning of words: implications for the visual word form area hypothesis. J Cogn Neurosci 19:1643-1655. CrossRef Medline

Xue G, Chen C, Jin Z, Dong Q (2006a) Language experience shapes fusiform activation when processing a logographic artificial language: an fMRI training study. Neuroimage 31:1315-1326. CrossRef Medline

Xue G, Chen C, Jin Z, Dong Q (2006b) Cerebral asymmetry in the fusiform areas predicted the efficiency of learning a new writing system. J Cogn Neurosci 18:923-931. CrossRef Medline
Zeineh MM, Engel SA, Thompson PM, Bookheimer SY (2003) Dynamics of the hippocampus during encoding and retrieval of face-name pairs. Science 299:577-580. CrossRef Medline

Zhang M, Li J, Chen C, Mei L, Xue G, Lu Z, He Q, Wei M, Dong Q (2013) The contribution of the left mid-fusiform cortical thickness to Chinese and English reading in a large Chinese sample. Neuroimage 65:250-256. CrossRef Medline

Zhu B, Chen C, Loftus EF, Lin C, He Q, Chen C, Li H, Xue G, Lu Z, Dong Q (2010) Individual differences in false memory from misinformation: cognitive factors. Memory 18:543-555. CrossRef Medline 